\title{
Cross-Cultural Communication- Expression Difference between Chinese and Japanese languages
}

\author{
Dongqing Guo ${ }^{1, a}$, Wei Tian ${ }^{1, b, *}$ and Ruonan Wang ${ }^{1, c}$ \\ ${ }^{1}$ Harbin University of Science and Technology (HUST), Harbin,150080, China \\ a 15104565093@163.com, b 1093728025@qq.com,c ligongwangruonan@163.com
}

Keywords: Cross-Cultural, Expression Difference, Chinese and Japanese languages

\begin{abstract}
As we know that the Cultural Differences between China and Japan exist, if we don't know the expression of each other ,it will cause misunderstandings. To make the communication goes well and successfully, we need to clarify expression differences. In this article, we will discuss from following aspects.
\end{abstract}

\section{Introduction}

Along with the development of economy globalization, the communication and collide of each country deepen continuously. China and Japan are Asian countries, and neighboring country. Since ancient times, in economic, political or cultural, the communication exchanged frequently. And the connection was close. As everyone knows, nowadays Japan belongs to developed country, and China as an up-and-coming youngster depends its untiring efforts, gradually stepping into developed country ranks. Therefore, in future the two countries are sure to have an interaction and build much closer relations. As we all know, the language medium as the civilization foundation of country and nationality, it reflects the word view, natural view and an outlook on life about this ethnic group. For this reason, to make the communication goes successfully, we need to understand expression difference perfectly.

\section{The Influence of National Character on Language Expression}

The Concept of National Character. In a manner of speaking, National character is that in the process of formation and development, the psychology that condensed by each nationality, almost shows in nation culture, and is a common feature of nation, the formation of a national character is a long-term and complicated process of development and transformation, is influenced by many factors, and in it, the most important factor is the national culture and history [1].

The Historical Culture and National Character of China and Japan. China is one of the world's four great ancient civilizations, has a long history, dating back to 5000 years ago, has the vast territory, many nationalities. And the culture is wide-ranging and profound, of long standing and well established. Although it suffered long-term aggression and war persecute, seeing from the absorption of foreign advanced culture, still have a strong self-esteem and self-confidence there, seeing at a respectful distance. Therefore, in language expression, we can feel that they are graceful and poised, full of confidence.

Japan is a small island nation, surrounded by sea, has never suffered aggression and colonization, since Tang Dynasty, they started to absorb foreign culture continously and actively. Since 68\% of the island area are mountains, land area is narrow and natural resources are limited relatively. In addition, it situated at plate boundary zone, Earthquakes occur frequently. they must unit as one, work together, share together, resist natural disasters. For thousands of years, the group 
consciousness and the peaceful consciousness came into being and deeply rooted in Japanese ideology. also has great influence on their behavior. For example, considerate, modest and gentle, self-restraint, refined and courteous. These consciousness and personality are also reflected in language expression accordingly, like euphemism, humility.

\section{From the Perspective of The Characteristics of Language to See the Differences of Language Expression Between China and Japan}

American psychologist Skinner (Burrhus Frederic Skinner) proposed the definition of language action: the language action of human behavior is only stimulus and response. Stimulus is something that is seen, heard, and felt. And response is the words that are spoken [2].

In a manner of speaking, the characteristics of Japanese language action have "negative" feature, they don't express their meaning clearly. In the exchange process, they are used to half said, leaving lingering sound to make other people guess. Japanese people pay more attention to the "implication", (action, expression etc. besides language). The master in literature on Japanese aestheticist trend named Junichirou Tanizaki once evaluate his nationality that our people are not good at expression. [3]. Next I will explain by examples.

Silence Is Golden. In japan, being scanty of words is not a bad thing, on the contrary, it will leave a good impression that you are a restrained person. Japanese doesn't think that being scanty of words means that you have problem with personality or shame. sometimes taciturn will make people feel that you are modest. Among Japanese, there are a lot of related proverbs, such as, talking people cannot work so well, etc.

Japanese Is Not Good at Arguing. Whether Japanese people or Japanese language, we can know that they do not like argument from heart. As we all know, Japanese are yamato nation, quiet and steady. and are not used to impose their own ideas on others, and don't force others to do something that they don't want to do. and they will not say real ideas or thoughts out, never show them on face. Japanese very care "heart to heart", "be sensitive". and other psychological activities. The following is my work experience in Japan, Department meeting lasted almost 50 minutes, it was divided into three parts: leadership speech, Q\&A, personal opinions. Totally 12 Participants, me and the other Chinese colleague, and the rest are Japanese colleagues. After the leader's speech, it's Q\&A session, we asked a lot of questions. But the session of personal opinions, only me and the other Chinese colleague said our ideas out, other Japanese colleagues did not speak, remained silent. This scene made me very impressed. This is very different from China.

The Ambiguous Expression of Japanese. Ambiguous expression is one of the salient features of Japanese language and culture. Japan is a nation that only has one minority. Everyone lives on a small island, working together and living together, whoever is not willing to contradict and conflict with each other. And among them there are complicated and delicate feelings, a smile, a wink or a simple action, can make each other understand. Next I will show representative examples to illustrate.

1 when asked by somebody that can you speak English. In this occasion, Japanese will not say that I can speak English or I cannot, or how much I know about English. Instead, they just say that English is not good.

2 when invited to dinner by somebody, if don't want to go, they will not refuse directly like I don't want to go or I don't want to have dinner with you. and instead they often say that tomorrow will be not good, or I have something to deal with etc.

3 when asked for some advices, they will not give a clear judgment. often use fuzzy words at the end of sentence to make expression ambiguously. such as:" maybe it should be” or” maybe it looks 
like” or” I don’t know too much about this, but maybe right”, etc.

In contrast, China advocates aboveboard and straightforward, will give a clear expression of their views. When they ask somebody, they hope to be given a clear bright answer. Obviously, China and Japan are different in this respect. If we do not know this, we cannot communicate smoothly. The following describes my personal experience. I am a fast speaker, once I was told by Japanese colleague that you speak so fast. At that time, I didn't show any responses, nodded and buried into work. But turning back to think about his true meaning, he might not understand what I said, and hoped me to say again.

\section{From Codes Of Language To See The Differences Of Language Expression Between China And Japan}

In the communication activities, even if we can speak fluent Japanese, but there are a lot of people cannot communicate with Japanese well. Why this happened? Have you thought about this? In my opinion, I think the reason is that we do not understand the language habits and the non-written hidden rules each other. Next I will use specific examples to analysis.

The Differences in Topic Selection. Japan is an island, surrounded by the sea. Weather is changing all the time, so Japanese are easy to influenced by weather, they care weather changes very much. In the greeting, they often say" it's been rainy recently" or "it is so cold" etc. however in China, since ancient times, there was a proverb "Food is the first necessity of the people". Therefore, when we meet somebody, we often say "Have you finished lunch?” or "you are getting thinner”, etc.

Here let's look at a research by Fei Peng, the title is topic selection between Chinese and Japanese [4].

A Inquiry about Family Membership (Japanese 2\% Chinese 53\%)

B Introduce family members (Japanese 20\% Chinese 70\%)

C Ask about accommodation (Japanese 20\% Chinese 85\%)

D Inquiry about job (Japanese 19\% Chinese 65\%)

E Inquiry about income (Japanese 0\% Chinese 35\%)

From the data survey, we can see that topic selection is very different. Therefore, cultural communication is not just changing languages, we must understand the cultural customs and backgrounds.

Differences in Expression Habits. In Chinese, we prefer to use "volition expression" and "transitive verb ". However, Japanese prefer to obey nature, pay more attention on Harmonious living with each other, are not used to express their ideas. Therefore, in Japanese language, Japanese people are more inclined to "state representation", like to use "intransitive verb". For example, the sunset make the west sky red. Japanese will make "sunset" as a reason, it changes into: because of the sunset, the west sky became red.

In addition, Chinese tend to "fact expression", but Japanese are more inclined to "standpoint expression." For example: His wife ran away. some Japanese learners who do not understand this point will say: His wife ran away. "His wife" is the subject, and the verb "ran away". But if we say so, cannot express the meaning that he was betrayed by his wife. The correct expression should be that he was betrayed by his wife who ran away with other man. Using a passive position to express" he was betrayed"[5]. 


\section{From the Etiquette of Language to See the Differences of Language Expression Between China and Japan}

In Japanese study, in addition to grammar, there are a lot of conventional rules that we need to learn. For example, the politeness. There are a lot of honorifics in Japanese language, respectful(sonkeyigo), humble(kenjougo), polite(teineigo). and the use of honorifics differs in thousands of ways between the ages. If we use the honorifics correctly, we can easily get closer with Japanese people in conversation. the next I will expatiate on this point in detail.

The Etiquette of First Meet. In Japan, when people introduce strangers, elders or friends, we will see that the Japanese become nervous in a flash, and correct posture, nod and give a salute to each other. Especially in business, receiving business card from others, hold it with hands, Squatting down a bit, nod and salute modestly [6].

The Humility of Japanese. In Japanese, there are so many apologies words and thanks words. For example, the words to express apology: I'm sorry, my apology, excuse me, please forgive me, it's my fault, I was careless, etc. the words to express thanks: Thank you, thanks a lot, I appreciate it very much, It's very kind of you. etc. Japanese are used to express themselves with a low profile, often say sorry or thank you.

In addition, Japanese also like to show "step back" to others. For example: I truly appreciate your help on this last occasion (o sewa ni na ri ma su). when I worked at Lenovo, I picked up phone from Japanese every time, I would hear this word at the beginning. and I felt confused, so I asked Japanese colleague why they said that. and she told me that whether he/she can help, if we say so, speaker feels that things can proceed smoothly, and he/she is willing to help me.

\section{Summary}

From the above narrative, we can know that the express cultural differences between Chinese and Japanese exist objectively, and the differences reflect different cultural patterns and cultural mentality of the two peoples. Therefore, in cross-cultural communication, we cannot evade these differences, On the contrary, we should take a respectful, positive, and tolerant attitude, understand the cultural connotation and background deeply, get to the root of the problem. Only in this way, the cross-cultural communication can carry on smoothly, we can promote the cultural exchanges between the two peoples.

\section{References}

[1] Tan ZhiSong "Ethnic Education Research", 2008, 19 (6): 12-16

[2] N. Chomsky Wang Zongyan "Contemporary Linguistics" 1982 the second period

[3] Junyitilo Tanizaki 《Article Reading》1996/2/18 Revision Chuokoron-sha press

[4] [7] Peng Fei The Study about Japanese language habits that trouble foreigner IZUMI SHOIN, 1991: $175 \sim 176$

[5] Wang XiuWen. Chinese and Japanese language translation and cross-cultural communication [C].

Beijing: World Knowledge Publishing House, 2006 first chapter $11 \sim 17$

[6] Wang Nan Nankai University Press, 1st Edition (January 1, 2011) Chapter II 102 104 